\title{
Spatial Clustering of Maternal Health Services Utilization and Its Associated Factors in Tanzania: Evidence From Tanzania Demographic Health Survey 2015-16
}

Blanka Thobias Assenga ( $\nabla$ thobiasblanka@gmail.com )

University of Dar es Salaam https://orcid.org/0000-0002-5844-6924

Amina Suleiman Msengwa

University of Dar es Salaam College of Arts and Social Sciences

Maurice Chakusaga Mbago

University of Dar es Salaam College of Arts and Social Sciences

Research article

Keywords: Cluster detection, maternal health and spatial analysis

Posted Date: December 2nd, 2020

DOI: https://doi.org/10.21203/rs.3.rs-117861/v1

License: (9) This work is licensed under a Creative Commons Attribution 4.0 International License. Read Full License 


\section{Abstract}

Background: Maternal healthcare services are major component for the health outcomes of the pregnant woman in making sure the deaths of mother and child are prohibited. This study aimed to examine the spatial clustering of maternal health care services utilization and the associated factors in Tanzania.

Methods: The study utilized the Tanzania Demographic Health Survey and Malaria Indicators Survey 2015-16 data. The study carried out to 7,013 women aged between 15 and 49 years who had a live birth in the five years preceding the survey. Spatial analysis was done using the Bernoulli model through Kullodorff scan statistics, and multiple logistic regression analysis was employed to identify the predictors of maternal health services utilization

Results: Spatial variations of antenatal care visit and delivery care across the regions was observed. Spatial scan statistic identified high utilization performing cluster for antenatal care centroid in Morogoro Region [RR=1.67, $p<0.001]$ and low utilization in Kaskazini Pemba Region [RR $=0.38, p<0.001]$. For delivery care utilization, high utilization was observed in Mtwara Region [RR=1.83, $p<0.001]$ and low utilization in Kigoma Region [RR=0.41, $P<0.001]$. Utilization of antenatal and delivery care services was higher among women from the richest households, with fewer children, living in urban areas and had acquired a higher education level.

Conclusion: Results permit more insight into the differences in maternal health service utilization in relation to demographic characteristics in the country. In addition, findings highlight areas with low utilization performing clusters. Such finds are beneficial in the implementation of policy and intervention to expand maternal health care uptake in cross the regions.

\section{Background}

Maternal mortality has remained global health challenges in developing countries (1). The report revealed that complication during delivery and pregnancy period take the lives of millions of women every year. It has been also observed that between 1990 and 2015 more than 10.7 million women die due to birth complication (2). The situation is worse in Sub-Saharan countries because many pregnant women cannot access health facilities at the right time and in the right place (3). Low and middle-income countries have attempted several techniques to reduce the existing problem. Up to now, very few strategies have managed to overcome the challenge (4). In Tanzania, the current report shows that the estimated maternal mortality rate was 556 per 100,000 live births (5). It implies that Tanzania is still far from Sustainable Development Goals (SDG) targets of decreasing maternal mortality rate to 70 per 100,000 live births (1).

There has been significant research in the world to understand the causes of maternal mortality. For example, it was found that low quality of care and poor accessibility of maternal health care services as the source of the maternal mortality $(6,7)$. Similar findings have reported the inadequacy of quality of maternal health care services throughout pregnancy, delivery and the postpartum $(8,9)$. Maternal health care services (MHS), including Antenatal care (ANC) delivery care and the postpartum period, are proven maternal health indicators that can reduce maternal mortality and taken as major components of safe motherhood (10). Previous studies have used maternal health indicators as a pathway to track the progress of Sustainable Development Goal (SDGs) toward maternal mortality reduction $(11,12)$. In most developing countries data on maternal 
mortality are not readily available and many researchers have been using maternal health care services indicators as proxies for maternal mortality (13).

Various studied indicates that many factors are influencing the utilization of maternal health services among pregnant women including demographic and household characteristics (14-16). Some of the researchers included demographic characteristics in their studies but the location of the households and distance to health facilities were not considered (17-19). The two variables are important because for balancing resources which affect the utilization of maternal health care services in the country (20).

Different spatial statistical analyses and geographical information system have been progressively used in epidemiology to examine the disease and non-disease distribution patterns and also the associations between health events and correlates (21-23). Although research on spatial patterns has focused on the disease rather than non-disease health outcome $(23,24)$. The geographic variation of maternal health care utilization would provide information for policy-makers and planners in the health sectors to target the use of limited resources of maternal health indicators in risk areas. Therefore, this paper examines the spatial clustering of maternal health care services utilization and their determinants among reproductive women aged 15-49 years in Tanzania.

\section{Methods}

\section{Study design}

This study extracted data from a national population-based survey of 2015-16 (25). An individual data set of reproductive women aged between 15 and 49 years and GPS files were downloaded from www.dhsprogram.com. The location (latitude and longitude) of the individual from the GPS data set were merged with the individual data using the cluster identification number.

\section{Study population}

The target population was all women of childbearing age between 15 to 49 years. The focus was on women who had a live birth in the five years preceding the survey. The most recent delivery was considered for women with two or more live births during the five years.

\section{Sampling procedure and sample size}

The sample was based on enumeration areas (EAs) of the 2012 Tanzania Population and Housing Census (26). A total of 608 clusters and 13,376 households were selected. All women aged between 15 and 49 years in the households were qualified for the interview. A total of 13,266 women were identified of which 7,013 reproductive women aged 15 and 49 years who had given birth in the past five years preceding the survey were included in this study.

\section{Measures}

Variables used in this study were obtained after reviewing various literature. Two outcome measures of maternal health care services were considered; antenatal and delivery care. 
ANC visit was coded as,

$$
Y_{i}=\left\{\begin{array}{l}
1 \text { if the woman had attended at least } 4 \text { ANC visit } \\
0, \text { otherwise }
\end{array}\right.
$$

and place of delivery was coded as,

$$
Y_{i}=\left\{\begin{array}{l}
1 \text { if the woman delivery in health facility } \\
0, \text { otherwise }
\end{array}\right.
$$

Explanatory variables included the area of residence, age of the women, education level, household wealth index, marital status and parity.

\section{Data analysis}

The extracted data were analyzed using STATA version 14 and SaTScan version 9.8. The univariate and bivariate analysis was used to obtain women's demographic characteristics and the association between the outcome variables and independent variables respectively. The multiple logistic model determined the effect of collective independent variables on the outcome variables. Odds Ratios (OR) and 95\% Confidence Interval (Cl) were computed to measure the effect of explanatory variables on the outcome variable.

Kulldorff's Spatial Scan statistics method was applied to detect clusters with high and low utilization of antenatal and delivery care. The maximum likelihood of having high utilization of antenatal and delivery care denoted the performing cluster. Other clusters apart from the most likely cluster were considered as the secondary clusters. The method arranges these clusters depending on the value of likelihood ratio test statistic and p-values. The Monte Carlo hypothesis testing provided the p-values by associating the rank of maximum likelihood of the actual dataset with that of the random dataset (27). This study defines the maximum cluster with a size of $50 \%$ of the total population.

A Bernoulli model was used to identify events occurred at a particular place whether the women use maternal health care services (ANC visit and health facility delivery) or not represented by a 0/1 variable. Reproductive women aged between 15 and 49 years who had given birth in the past five years preceding the survey in the household but had never or attended less than the recommended number of ANC visits, and use non-health facility for delivery were included as a control.

\section{Ethical considerations}

The Medical Research Coordinating Committee (MRCC) granted ethical approval for DHS to conduct the survey. The approval to use the data for this study was requested and received from the DHS MEASURE.

\section{Results}

\section{Sample characteristics}


Results in Table 1 presents the social-demographic characteristics of women involved in this study. It was revealed that $72.99 \%$ of respondents resided in rural areas and $26.01 \%$ resided in urban areas. It was noted that $65.72 \%$ of women were aged between 20 and 34 years and $7.81 \%$ were below 20 years. As regards education, it was found that $60.62 \%$ of the respondents had primary education and $19.48 \%$ never attended any formal education. It was further revealed that $21.97 \%$ of women were from richer households, while $20.52 \%$ were from poorest households. Findings indicated further that $81.55 \%$ of the women were married and $6.43 \%$ were single. Regarding the number of children, the results indicated that $71.57 \%$ of women had between one to four children. About $50 \%$ of women adhered to the suggested number of antenatal care visits and the remaining $50 \%$ of pregnant women did not adhere to the suggested number of antenatal care visits. The percentage of the respondents was higher (67.20\%) among those who reported using health facility for delivery and it was $32.80 \%$ for those who did not use health facility for delivery.

\section{Identified clusters with high utilization of antenatal and delivery care services}

A total of 608 sample points for 2015-16 TDHS-MIS data was used to test hypotheses for high and low utilization of maternal health care. Clusters with high utilization of more than four antenatal care visits and health facility delivery care are presented in Table 2 and Figure 1. A significant cluster with the high utilization of antenatal care visits was identified. The most likely cluster was detected with 305 sample points centralized at coordinates $\left(-8.15383^{0} \mathrm{~S}, 36.68966^{\circ} \mathrm{E}\right)$ in Morogoro Region. The cluster covers the radius 439.86km, which include Manyara, Tanga, Pwani, Lindi, Mtwara, Ruvuma, Njombe, Mbeya, Iringa, Singida, Dodoma, Tabora, Dar es Salaam, Kusini Unguja, Kaskazini Unguja and Kilimanjaro regions. Women in the most likely cluster were $67 \%$ more likely to attend more than four antenatal care visits throughout the pregnancy period compared to women in other clusters [RR=1.67, $p<0.001]$.

Regarding the place of delivery, the study identified four clusters. The most likely cluster with sample points 210 was centralized at coordinate $\left(-10.9218^{\circ} \mathrm{S}, 38.11758^{\circ} \mathrm{E}\right)$ in Mtwara Region. The cluster covers the radius of $545 \mathrm{~km}$, which include Mbeya, Iringa, Dodoma, Morogoro, Pwani, Kusini Unguja, Dar es Salaam, Lindi, Njombe, Ruvuma and Mtwara region. Women in the most likely cluster were $83 \%$ more likely to delivery at a health facility compared to women in other clusters [RR=1.83, $p<0.001]$.

\section{Identified clusters with low utilization of antenatal and delivery care services.}

This study further identified eight and fifteen significant clusters with the lowest utilization of antenatal care and delivery care, respectively, as shown in Table 3 and Figure 2. The most likely cluster for lowest utilization of antenatal care services with 13 sample points was centralized at coordinates $\left(-4.94153^{\circ} \mathrm{S}, 39.74770^{\circ} \mathrm{E}\right)$ in Kaskazini Pemba. The cluster covers a radius of 20.35 km, which included Kaskazini Pemba region only. Women in the most likely cluster were $62 \%$ less likely to have an adequate rate of the number of antenatal care visits compared to women in other clusters [RR=0.38, $p<0.001]$.

Concerning the place of delivery, the most likely cluster of low utilization of health facility delivery with 13 sample points was centralized at coordinates $\left(-3.19546^{\circ} \mathrm{S}, 30.86875^{\circ} \mathrm{E}\right)$ in Kigoma Region. The cluster covers a radius of $127.36 \mathrm{~km}$, which include Katavi, Tabora and Kigoma regions. Women in this cluster were $59 \%$ less likely to deliver at a health facility compared to women in other clusters [RR=0.41, $p<0.001]$. 


\section{Factors related to the utilization of antenatal care and delivery care services}

The finding of this study show residence areas, level of education, wealth index, the number of living children are significant for antenatal care utilization in both univariate and bivariate analysis (Table 4). The multiple logistic regression analysis shows that women with secondary and higher education level were $36 \%$ more likely to make more than four ANC visits service than uneducated women [AOR=1.36; $95 \% \mathrm{Cl}=1.14-1.62$ ]. It was also observed that women with primary education were $17 \%$ more likely to make more than four ANC visits than uneducated women $[A O R=1.17 ; 95 \% \mathrm{Cl}=1.03-1.33]$. The utilization of more than four ANC visits was relatively proportional to household-wealth status. Thus women from most affluent households were $38 \%$ more likely to adhere to the recommended number of ANC visits than those from richest households [AOR: 2.38, $95 \% \mathrm{Cl}=1.94-2.91]$. Women with more than five children were $40 \%$ less likely to utilize antenatal care services than women without children $[A O R=0.60,95 \% \mathrm{Cl}=0.36-0.99, \mathrm{p}<0.05]$.

The relationships between the socio-demographic characteristics and utilization of place of delivery are shown in Table 5. The results of the univariate and bivariate analysis indicate that residence, women age, level of education, household wealth index and the number of living children were related to the utilization of delivery services.

The results indicate that women who belong to rural areas were $54 \%$ less likely $[\mathrm{AOR}=0.46,95 \% \mathrm{Cl}=0.38-0.56]$ to use health facility delivery care than those in urban areas. Findings further revealed that women with secondary and higher educational level were $60 \%$ more likely to use health facility delivery care $[A O R=2.60$, 95\% Cl: 2.10-3.23] compared to uneducated women. Regarding wealth indices, the odds of health facility delivery care increased with an increase in household-wealth status. Thus, women from the richest wealth status were $40 \%$ more likely to use health facility for delivery relative to women in the poorest wealth status $[\mathrm{AOR}=5.40,95 \% \mathrm{Cl}=4.11-7.10]$.

\section{Discussion}

This study examined the spatial clustering of the utilization of maternal health care and its correlates among the reproductive women aged between 15 and 49 years in Tanzania. The results reveal significant spatial variation in the utilization of antenatal and delivery care services. Clusters with high and low utilization of antenatal care and delivery care were identified. The study identified Kaskazini Pemba and Kigoma as a region with a low utilization rate of antenatal and delivery care services respectively. These areas require significant effort to impart knowledge to improve the uptake rate of antenatal care visit and delivery care services. The influence of geographical variation in relative to maternal health care utilization was also noted in $(20,28,29)$.

The WHO endorsed that at least 69\% of low-risk expectant women in Sub-Saharan Africa must attend at least one ANC visit (28). In this study, the results indicated that $50.34 \%$ of the pregnant women have an inadequate number of antenatal care visits and $49.66 \%$ have an adequate number of antenatal care visits, which is low as compared to the WHO recommendation. Thus, more effort is required to progress the low rate of ANC care utilization. 
The study also reveals that rural women were less likely to utilize maternal health care services compared to urban women. These findings concur with the results of (30-34) which found the influence of residence on the utilization of maternal health care. This difference may be due to availability of better transportation systems to access maternal health services in the urban area.

Regarding the level of education, use of antenatal care and delivery care are in line with those presented by $(15,17,18,35)$ that education significantly influences the use of maternal health care. This may due to the reason that educated women are more likely to understand the advantage of using the components of maternal health services during the pregnant period; therefore, it increases the likelihood of using it.

It is also observed that wealth indices are statistically associated with the use of maternal health services. Similarly, the use of maternal health care increases with the wealth quartile of the women, whereby women from the wealthiest households are more likely to use antenatal care and delivery care than those in more impoverished households. Results are supported by numerous scholarships that household wealth status influences the use of maternal health care services $(29,36)$.

Moreover, there is a significant relationship between the number of living children and the use of antenatal care. The results have shown that the odds of women attending ANC visit decrease as the number of children increases. Literature shows that women with more children have a habit of using maternal health services less frequently compared to women with few children $(15,33,34)$. This may due to the knowledge concern the pregnancy for a new mother that they can have a fear of risk associated with her pregnancy which will make her have frequent use of maternal health care.

\section{Conclusion}

This study points out that low utilization in maternal health care services is spotted in a specific area in Tanzania. Among the spotted clusters, Kaskazini Pemba and Kigoma regions appeared with low utilization of both antenatal and delivery care. Women from wealthy households, households with a fewer number of children, educated and residing in urban areas are more likely to use maternal health care. These results provide an adequate avenue in understanding the situations of antenatal care and delivery care utilization in the regions of Tanzania. The findings inform policymakers and health experts to implement effective and timely interventions in high-risk areas.

\section{Abbreviations}

ANC: Antenatal care; TDHS-MIS: Tanzania Demographic Health Survey and Malaria Indicator Survey; WHO: World Health Organization, AOR: Adjusted Odds Ratio.

\section{Declarations}

\section{Ethical approval and consent to participate}

The Medical Research Coordinating Committee (MRCC) granted ethical approval for DHS to conduct the survey. The approval to use the data for this study was requested and received from the DHS MEASURE. 
Availability of data and material

The utilized datasets are available upon request to www.dhsprogram.com.

\section{Consent of publication}

Not applicable

\section{Competing interests}

The authors declare that they have no competing interest.

\section{Authors' contributions}

BT has made substantial contributions to the conception, design of the work, drafting of the manuscript, analysis and interpretation of data. AM has provided her expertise on the use of SaTScan software on analysis of maternal health services utilization, and MM has provided editorial work and writing assistance. All authors read and approved the final manuscript.

\section{Acknowledgements}

Not applicable

\section{Author Details}

Department of Statistics, University of Dar es Salaam, Tanzania.

\section{References}

1. WHO. World health statistics 2016: monitoring health for the SDGs sustainable development goals. World Health Organization; 2016.

2. Alkema L, Chou D, Gemmill A, Hogan DR, Mathers C, Mills SL, et al. Trends in maternal mortality: 1990 to 2013-estimates by WHO, UNICEF, UNFPA, the World Bank, and the United Nations population division. The World Bank; 2014.

3. Lozano R, Naghavi M, Foreman K, Lim S, Shibuya K, Aboyans V, et al. Global and regional mortality from 235 causes of death for 20 age groups in 1990 and 2010: a systematic analysis for the Global Burden of Disease Study 2010. The Lancet. 2012;380(9859):2095-128.

4. Chou D, Inoue M, Mathers C, Moller AB, Oestergaard M, Say L, et al. Trends in maternal mortality: 1990 to 2010. WHO UNICEF UNFPA and the World Bank estimates allAfrica. 2012;12(9811):84.

5. TDHS. Tanzania Demographic and Health Survey and Malaria Indicator Survey (TDHS-MIS) 2015-16. TDHS; 2016.

6. Silal SP, Penn-Kekana L, Harris B, Birch S, Mclntyre D. Exploring inequalities in access to and use of maternal health services in South Africa. BMC health services research. 2012;12(1):120.

7. Jaribu JE. Implementation and evaluation of a health facility quality improvement intervention for maternal and neonatal health in Southern Tanzania [PhD Thesis]. University_of_Basel; 2016. 
8. Tunçalp Ö., Were WM, MacLennan C, Oladapo OT, Gülmezoglu AM, Bahl R, et al. Quality of care for pregnant women and newborns-the WHO vision. Bjog. 2015;122(8):1045.

9. Organization WH. Trends in maternal mortality: 1990 to 2013: estimates by WHO, UNICEF, UNFPA, The World Bank and the United Nations Population Division: executive summary. World Health Organization; 2014.

10. ML AN, Malonga F, Dramaix-Wilmet M, Donnen P. Determinants of maternal health services utilization in urban settings of the Democratic Republic of Congo-a case study of Lubumbashi City. BMC pregnancy and childbirth. 2012;12(1):66.

11. Atuoye KN, Amoyaw JA, Kuuire VZ, Kangmennaang J, Boamah SA, Vercillo S, et al. Utilisation of skilled birth attendants over time in Nigeria and Malawi. Global Public Health. 2017;12(6):728-743.

12. Kuuire VZ, Kangmennaang J, Atuoye KN, Antabe R, Boamah SA, Vercillo S, et al. Timing and utilisation of antenatal care service in Nigeria and Malawi. Global Public Health. 2017;12(6):711-727.

13. Storeng KT, Béhague DP. "Guilty until proven innocent": the contested use of maternal mortality indicators in global health. Critical Public Health. 2017;27(2):163-176.

14. Singh PK, Kumar C, Rai RK, Singh L. Factors associated with maternal healthcare services utilization in nine high focus states in India: a multilevel analysis based on 14385 communities in 292 districts. Health policy and planning. 2014;29(5):542-559.

15. Tarekegn SM, Lieberman LS, Giedraitis V. Determinants of maternal health service utilization in Ethiopia: analysis of the 2011 Ethiopian Demographic and Health Survey. BMC pregnancy and childbirth. 2014;14(1):161.

16. Shrestha G. Factors Affecting Maternal Health Care Services Utilization in Nepal: Insight from the Nepal Demographic Health Survey 2006 and 2011. Nepalese Journal of Statistics. 2017;1:55-72.

17. Gupta S, Yamada G, Mpembeni R, Frumence G, Callaghan-Koru JA, Stevenson R, et al. Factors associated with four or more antenatal care visits and its decline among pregnant women in Tanzania between 1999 and 2010. PloS one. 2014;9(7):e101893.

18. Lwelamira J, Safari J, Stephen A. Utilization of maternal postnatal care services among women in selected villages of Bahi District, Tanzania. Current Research Journal of Social Sciences. 2015;7(4):106111.

19. Mohan D, Gupta S, LeFevre A, Bazant E, Killewo J, Baqui AH. Determinants of postnatal care use at health facilities in rural Tanzania: multilevel analysis of a household survey. BMC pregnancy and childbirth. 2015;15(1):282.

20. Ansariadi A, Manderson L. Antenatal care and women's birthing decisions in an Indonesian setting: does location matter? Rural and remote health. 2015;15(2):45.

21. Briggs DJ, Elliott P. The use of geographical information systems in studies on environment and health. World health statistics quarterly Rapport trimestriel de statistiques sanitaires mondiales. 1995;48(2):85.

22. Elliott $P$, Wartenberg D. Spatial epidemiology: current approaches and future challenges. Environmental health perspectives. 2004;112(9):998-1006.

23. Warden CR. Comparison of Poisson and Bernoulli spatial cluster analyses of pediatric injuries in a fire district. International Journal of Health Geographics. 2008;7(1):51. 
24. Meliker JR, Jacquez GM, Goovaerts P, Copeland G, Yassine M. Spatial cluster analysis of early-stage breast cancer: a method for public health practice using cancer registry data. Cancer Causes \& Control. 2009;20(7):1061-1069.

25. Ministry of Health E, Children (MoHCDGEC)[Tanzania Mainland], ICF. Tanzania Demographic and Health Survey and Malaria Indicator Survey (TDHS-MIS) 2015-16. MoHCDGEC, MoH, NBS, OCGS, and ICF Dar es Salaam, Tanzania, and Rockville ...; 2016.

26. Tanzania, NBS. 2012 population and housing census. 2013;

27. Kulldorff M. A spatial scan statistic. Communications in Statistics-Theory and methods. 1997;26(6):1481-1496.

28. Gayawan E. A Poisson regression model to examine spatial patterns in antenatal care utilisation in Nigeria. Population, Space and Place. 2014;20(6):485-497.

29. Yeneneh A, Alemu K, Dadi AF, Alamirrew A. Spatial distribution of antenatal care utilization and associated factors in Ethiopia: evidence from Ethiopian demographic health surveys. BMC pregnancy and childbirth. 2018;18(1):1-12.

30. Abosse Z, Woldie M, Ololo S. Factors influencing antenatal care service utilization in hadiya zone. Ethiopian Journal of Health Sciences. 2010;20(2).

31. Dagne E. Role of socio-demographic factors on utilization of maternal health care services in Ethiopia [PhD Thesis]. Umelaa International School of Public Health; 2010.

32. Ochako R, Fotso J-C, Ikamari L, Khasakhala A. Utilization of maternal health services among young women in Kenya: insights from the Kenya Demographic and Health Survey, 2003. BMC pregnancy and childbirth. 2011;11(1):1.

33. Toan TK. Antenatal and delivery care utilization in urban and rural contexts in Vietnam. A study in two health and demographic surveillance sites. Gothenburg, Sweden. 2012;

34. Tsawe M, Moto A, Netshivhera T, Ralesego L, Nyathi C, Susuman AS. Factors influencing the use of maternal healthcare services and childhood immunization in Swaziland. International journal for equity in health. 2015;14(1):32.

35. Mrisho M, Schellenberg JA, Mushi AK, Obrist B, Mshinda H, Tanner M, et al. Factors affecting home delivery in rural Tanzania. Tropical medicine \& international health. 2007;12(7):862-872.

36. Chimankar DA, Sahoo H. Factors influencing the utilization of maternal health care services in Uttarakhand. Studies on Ethno-Medicine. 2011;5(3):209-216.

37. Abera M, Belachew T. Predictors of safe delivery service utilization in Arsi Zone, South-East Ethiopia. Ethiopian Journal of health sciences. 2011;21(3).

38. Ghaffar A, Pongponich S, Ghaffar N, Mehmood T. Factors associated with utilization of antenatal care services in Balochistan province of Pakistan: An analysis of the Multiple Indicator Cluster Survey (MICS) 2010. Pakistan journal of medical sciences. 2015;31(6):1447.

\section{Tables}

Table1: Socio-demographic characteristics of selected women $(n=7,013)$, TDHS-MIS 201516

Page 10/21 


\begin{tabular}{|c|c|c|}
\hline Variables & Codes & Number (\%) \\
\hline & $1=$ urban & $1824(26.01)$ \\
\hline \multirow[t]{2}{*}{ Residence } & $2=$ rural & $5189(72.99)$ \\
\hline & $1=$ Less than 20 & $548(7.81)$ \\
\hline \multirow[t]{3}{*}{ Women age } & $2=20-34$ & $4609(65.72)$ \\
\hline & $3=35-49$ & $1856(26.47)$ \\
\hline & $0=$ No education & $1366(19.48)$ \\
\hline \multirow[t]{4}{*}{ Educational level } & $1=$ Primary education & $4251(60.62)$ \\
\hline & 2 = Secondary and Higher & 1396(19.91) \\
\hline & 1 = Poorest & $1439(20.52)$ \\
\hline & 2 = Poorer & 1356(19.34) \\
\hline \multirow[t]{4}{*}{ Wealth } & $3=$ Middle & $1376(19.62)$ \\
\hline & 4 = Richer & $1541(21.97)$ \\
\hline & $5=$ Richest & $1301(18.55)$ \\
\hline & $0=$ Single & $45(6.43)$ \\
\hline \multirow[t]{3}{*}{ Marital status } & $1=$ Married & $5719(81.55)$ \\
\hline & 2 = Widowed & $843(12.02)$ \\
\hline & $0=1$ & 71(1.01) \\
\hline \multirow[t]{2}{*}{ No of living Children } & $1=1-4$ & $5019(71.57)$ \\
\hline & $2=5+$ & $1923(27.42)$ \\
\hline
\end{tabular}




\begin{tabular}{|llr|} 
Number of ANC visits & $0=$ Inadequate visits (less than 4 visit) & $3530(50.34)$ \\
& $1=$ Adequate visits (more than 4 visit) & $3483(49.66)$ \\
\hline Place of delivery & $0=$ Non-health facility & $2300(32.80$ \\
\hline 1 & $=$ Health facility & $4713(67.20)$ \\
\hline
\end{tabular}

Table 2: Clusters with the high utilization of antenatal care and delivery care services TDHS-MIS 2015-16

\begin{tabular}{|c|c|c|c|c|c|c|c|c|}
\hline \multicolumn{9}{|c|}{ Number of antenatal care } \\
\hline $\begin{array}{l}\text { Cluster } \\
\text { Type }\end{array}$ & Centroid & Latitude & Longitude & Radius & $\begin{array}{l}\text { Sample } \\
\text { points }\end{array}$ & $\begin{array}{l}\text { P- } \\
\text { Value }\end{array}$ & $\begin{array}{l}\text { Relative } \\
\text { Risk }\end{array}$ & $\begin{array}{l}\text { Region } \\
\text { with } \\
\text { centroid }\end{array}$ \\
\hline $\begin{array}{l}\text { Most } \\
\text { Likely }\end{array}$ & 90 & -8.15383 & 36.68966 & 439.86 & 305 & 0.000 & 1.67 & Morogoro \\
\hline \multicolumn{9}{|c|}{ Delivery care } \\
\hline $\begin{array}{l}\text { Cluster } \\
\text { type }\end{array}$ & Centroid & Latitude & Longitude & Radius & $\begin{array}{l}\text { Sample } \\
\text { points }\end{array}$ & $\begin{array}{l}\text { P- } \\
\text { Value }\end{array}$ & $\begin{array}{l}\text { Relative } \\
\text { Risk }\end{array}$ & $\begin{array}{l}\text { Region } \\
\text { with } \\
\text { centroid }\end{array}$ \\
\hline $\begin{array}{l}\text { Most } \\
\text { likely }\end{array}$ & 196 & -10.92183 & 38.11758 & 545.00 & 210 & 0.000 & 1.83 & Mtwara \\
\hline Secondary & 23 & -3.24586 & 36.98748 & 39.09 & 14 & 0.000 & 1.69 & Tanga \\
\hline Secondary & 70 & -5.07954 & 39.09726 & 69.27 & 12 & 0.000 & 1.53 & Kilimanjaro \\
\hline Secondary & 390 & -2.54834 & 32.92563 & 8.16 & 5 & 0.005 & 1.64 & Mwanza \\
\hline
\end{tabular}

Table 3: Clusters with the low Utilization of Antenatal Care and Delivery Care, TDHS-MIS 2015-16 


\begin{tabular}{|c|c|c|c|c|c|c|c|c|}
\hline \multicolumn{9}{|c|}{ Number of antenatal care } \\
\hline $\begin{array}{l}\text { Cluster } \\
\text { Type }\end{array}$ & Centroid & Latitude & Longitude & Radius & $\begin{array}{l}\text { Sample } \\
\text { points }\end{array}$ & $\begin{array}{l}\text { P- } \\
\text { Value }\end{array}$ & $\begin{array}{l}\text { Relative } \\
\text { Risk }\end{array}$ & $\begin{array}{l}\text { Region } \\
\text { with } \\
\text { centroid }\end{array}$ \\
\hline $\begin{array}{l}\text { Mostly } \\
\text { Likely }\end{array}$ & 587 & -4.94153 & 39.74770 & 20.35 & 13 & 0.000 & 0.38 & $\begin{array}{l}\text { Kaskazini } \\
\text { Pemba }\end{array}$ \\
\hline Secondary & 340 & -3.19546 & 30.86875 & 94.85 & 14 & 0.000 & 0.52 & Kigoma \\
\hline Secondary & 359 & -4.17777 & 32.03732 & 46.77 & 5 & 0.000 & 0.38 & Shinyanga \\
\hline Secondary & 604 & -5.33083 & 39.78779 & 6.40 & 4 & 0.000 & 0.27 & $\begin{array}{l}\text { Kusini } \\
\text { Pemba }\end{array}$ \\
\hline Secondary & 485 & -7.112338 & 31.43694 & 86.03 & 12 & 0.000 & 0.58 & Katavi \\
\hline Secondary & 399 & -2.163879 & 32.15195 & 72.04 & 12 & 0.000 & 0.56 & Kagera \\
\hline Secondary & 352 & -3.509063 & 33.12594 & 0.00 & 1 & 0.002 & 0.07 & Shinyanga \\
\hline Secondary & 492 & -2.993746 & 34.22590 & 40.64 & 8 & 0.038 & 0.64 & Simiyu \\
\hline \multicolumn{9}{|c|}{ Place of delivery } \\
\hline $\begin{array}{l}\text { Cluster } \\
\text { Type }\end{array}$ & Centroid & Latitude & Longitude & Radius & $\begin{array}{l}\text { Sample } \\
\text { points }\end{array}$ & $\begin{array}{l}\text { P- } \\
\text { Value }\end{array}$ & $\begin{array}{l}\text { Relative } \\
\text { Risk }\end{array}$ & $\begin{array}{l}\text { Region } \\
\text { with } \\
\text { centroid }\end{array}$ \\
\hline $\begin{array}{l}\text { Most } \\
\text { Likely }\end{array}$ & 337 & -5.18130 & 30.99442 & 127.36 & 13 & 0.000 & 0.41 & Kigoma \\
\hline Secondary & 492 & -2.99375 & 34.22590 & 77.74 & 19 & 0.000 & 0.54 & Simiyu \\
\hline Secondary & 526 & -2.94269 & 31.59055 & 102.51 & 25 & 0.000 & 0.59 & Geita \\
\hline Secondary & 594 & -5.32698 & 39.80520 & 43.24 & 29 & 0.000 & 0.63 & $\begin{array}{l}\text { Kaskazini } \\
\text { Pemba }\end{array}$ \\
\hline Secondary & 441 & -5.48361 & 37.25677 & 84.97 & 11 & 0.000 & 0.48 & Manyara \\
\hline Secondary & 292 & -5.70289 & 33.96951 & 63.02 & 3 & 0.000 & 0.45 & Tabora \\
\hline Secondary & 438 & -3.92048 & 36.51063 & 51.54 & 2 & 0.000 & 0.15 & Manyara \\
\hline Secondary & 39 & -3.02414 & 36.29140 & 0.00 & 1 & 0.000 & 0.00 & Arusha \\
\hline Secondary & 483 & -7.09008 & 31.165882 & 80.65 & 13 & 0.001 & 0.67 & Katavi \\
\hline Secondary & 529 & -5.86368 & 39.279874 & 10.62 & 7 & 0.002 & 0.54 & $\begin{array}{l}\text { Kaskazini } \\
\text { Unguja }\end{array}$ \\
\hline Secondary & 310 & -8.37629 & 32.048961 & 0.00 & 1 & 0.002 & 0.00 & Rukwa \\
\hline Secondary & 2 & -4.36409 & 35.852918 & 0.00 & 1 & 0.013 & 0.00 & Dodoma \\
\hline Secondary & 267 & -4.62602 & 34.683489 & 15.65 & 3 & 0.025 & 0.39 & Singida \\
\hline Secondary & 350 & -3.39605 & 32.943685 & 59.81 & 12 & 0.033 & 0.74 & Shinyanga \\
\hline
\end{tabular}


Table 4: Odds ratios and 95\% Confidence Interval (CI) by ANC care utilization, TDHS-MIS 2015-16 


\section{Covariates}

Residence

Urban

Rural

Women age group

$<20$

20-34

35-49

Level of education

No education

Primary education

Secondary and Higher

Wealth

Poorest

Poorer

Middle

Richer

Richest

Marital

Status

Single

$\begin{array}{ll}\text { Crude odds ratio } & \begin{array}{l}\text { Adjusted odds } \\ \text { ratio }\end{array} \\ \text { OR }(95 \% \mathrm{Cl}) & \text { AOR }(95 \% \mathrm{Cl})\end{array}$

Overall-P value

$<0.001$

Ref

Ref

$0.55(0.49-$

$0.61)^{\star \star \star}$

0.94 (0.82 -1.09)
Ref

$1.19(1.00$

$-1.43)^{\star \star}$

$1.02(0.85-1.24)$
Ref

$1.12(0.93-1.35)$

$1.32(1.05$

$-1.65)^{\star \star}$ 


\begin{tabular}{|c|c|c|c|}
\hline Married & $0.88(0.72-1.06)$ & $1.11(0.91-1.36)$ & \\
\hline Widowed & $1.00(0.79-1.26)$ & $1.22(0.96-1.55)$ & \\
\hline No of living children & & & $<0.001$ \\
\hline 0 & Ref & Ref & \\
\hline $1-4$ & $0.99(0.62-1.58)$ & $0.92(0.57-1.50)$ & \\
\hline $5+$ & $\begin{array}{l}0.59(0.37- \\
0.94)^{\star \star}\end{array}$ & $\begin{array}{l}0.60(0.36- \\
0.99)^{\star \star}\end{array}$ & \\
\hline
\end{tabular}

Significance level: $* * *=p<0.01, * *=p<0.05, *=p<0.1$, Ref reference categories

Table 5: Odds ratios and 95\% Confidence Interval (Cl) by delivery care utilization, TDHS 2015-16 


\begin{tabular}{|c|c|c|c|}
\hline \multirow[t]{2}{*}{ Covariates } & Unadjusted & Adjusted & \multirow[t]{2}{*}{ Overall-P-value } \\
\hline & OR $(95 \% \mathrm{Cl})$ & AOR (95\%Cl) & \\
\hline & & & $<0.001$ \\
\hline \multicolumn{4}{|l|}{ Residence } \\
\hline Urban & Ref & Ref & \\
\hline Rural & $0.19(0.16-0.22)^{\star \star \star}$ & $0.46(0.38-0.56)^{\star \star \star}$ & \\
\hline & & & $<0.001$ \\
\hline \multicolumn{4}{|l|}{ Women age } \\
\hline$<20$ & Ref & Ref & \\
\hline $20-34$ & $0.96(0.79-1.16)$ & $0.86(0.70-1.07)$ & \\
\hline $35-49$ & $0.75(0.61-0.92)^{\star \star \star}$ & $1.20(0.93-1.55)$ & \\
\hline & & & $<0.001$ \\
\hline \multicolumn{4}{|l|}{ Level of education } \\
\hline No education & Ref & Ref & \\
\hline Primary education & $2.38(2.10-2.70)^{\star \star \star}$ & $1.70(1.49-1.94)^{\star \star \star}$ & \\
\hline Secondary and Higher & $7.6(6.28-9.15)^{\star \star \star}$ & $2.60(2.10-3.23)^{\star \star \star}$ & \\
\hline & & & $<0.001$ \\
\hline \multicolumn{4}{|l|}{ Wealth } \\
\hline Poorest & Ref & Ref & \\
\hline Poorer & $1.40(1.21-1.63)^{\star \star \star}$ & $1.37(1.17-1.59)^{\star \star \star}$ & \\
\hline Middle & $2.12(1.82-2.47)^{\star \star \star}$ & $1.85(1.58-2.16)^{\star \star \star}$ & \\
\hline Richer & $4.46(1.82-2.47)^{\star \star \star}$ & $2.80(2.35-3.34)^{\star \star \star}$ & \\
\hline Richest & $14.37(11.41-18.09)^{\star \star \star}$ & $5.40(4.11-7.10)^{\star \star \star}$ & \\
\hline Marital Status & & & 0.053 \\
\hline Single & Ref & Ref & \\
\hline Married & $0.48(0.38-0.61)^{\star \star \star}$ & $0.86(0.66-1.12)$ & \\
\hline Widowed & $0.58(0.45-0.77)^{\star \star \star}$ & $0.96(0.71-1.29)$ & \\
\hline No of living children & & & $<0.001$ \\
\hline 0 & Ref & Ref & \\
\hline $1-4$ & $1.20(0.73-2.00)$ & $\begin{array}{l}1.36(0.79-2.37) \\
\text { e } 17 / 21\end{array}$ & \\
\hline
\end{tabular}


Significance level: ${ }^{* *}=p<0.01, * *=p<0.05, *=p<0.1$, Ref reference categories

\section{Figures}

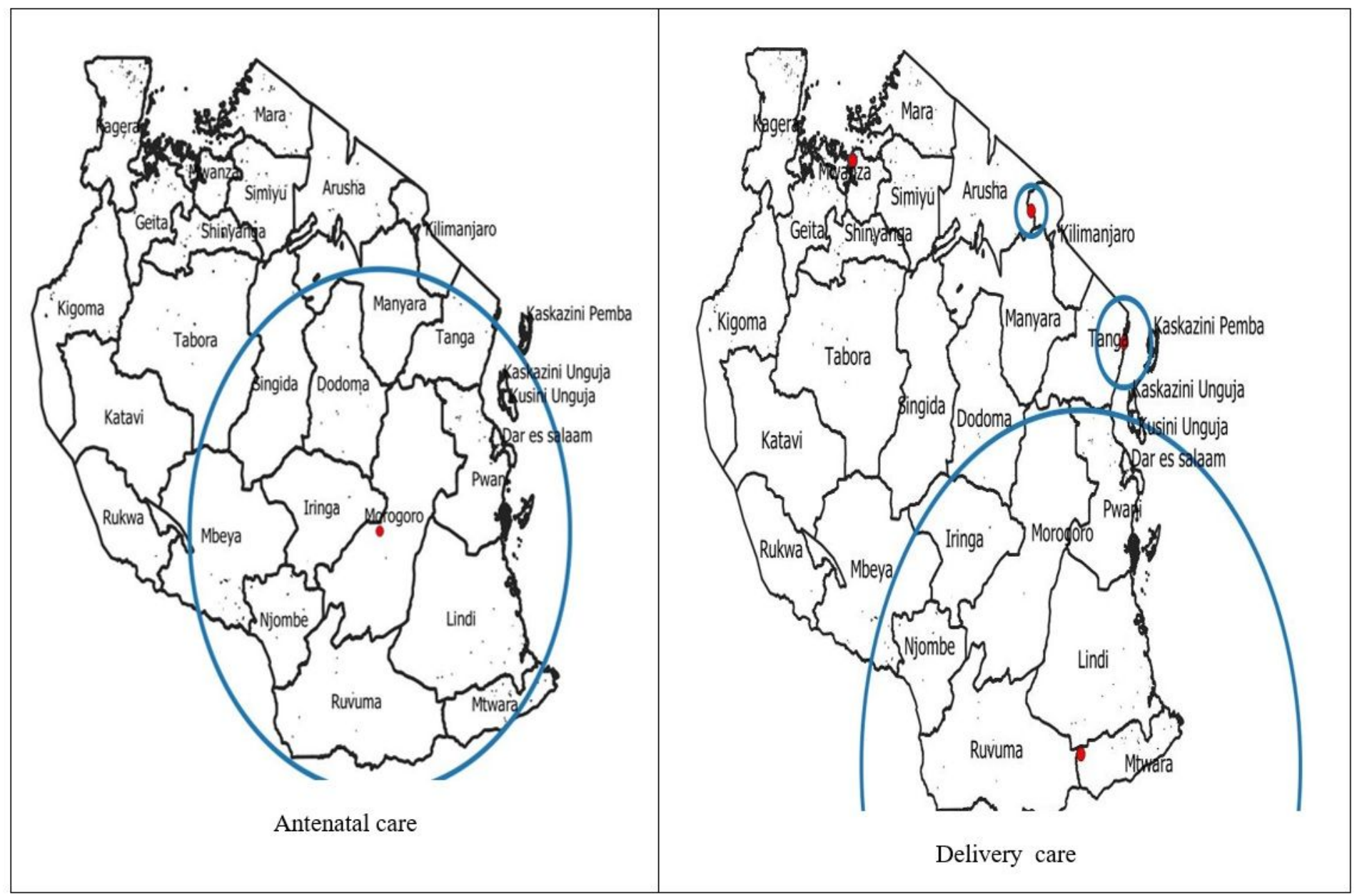

\section{Figure 1}

Clusters with the high utilization of antenatal care and delivery care from TDHS-MIS 2015-16 Note: The designations employed and the presentation of the material on this map do not imply the expression of any opinion whatsoever on the part of Research Square concerning the legal status of any country, territory, city or area or of its authorities, or concerning the delimitation of its frontiers or boundaries. This map has been provided by the authors. 


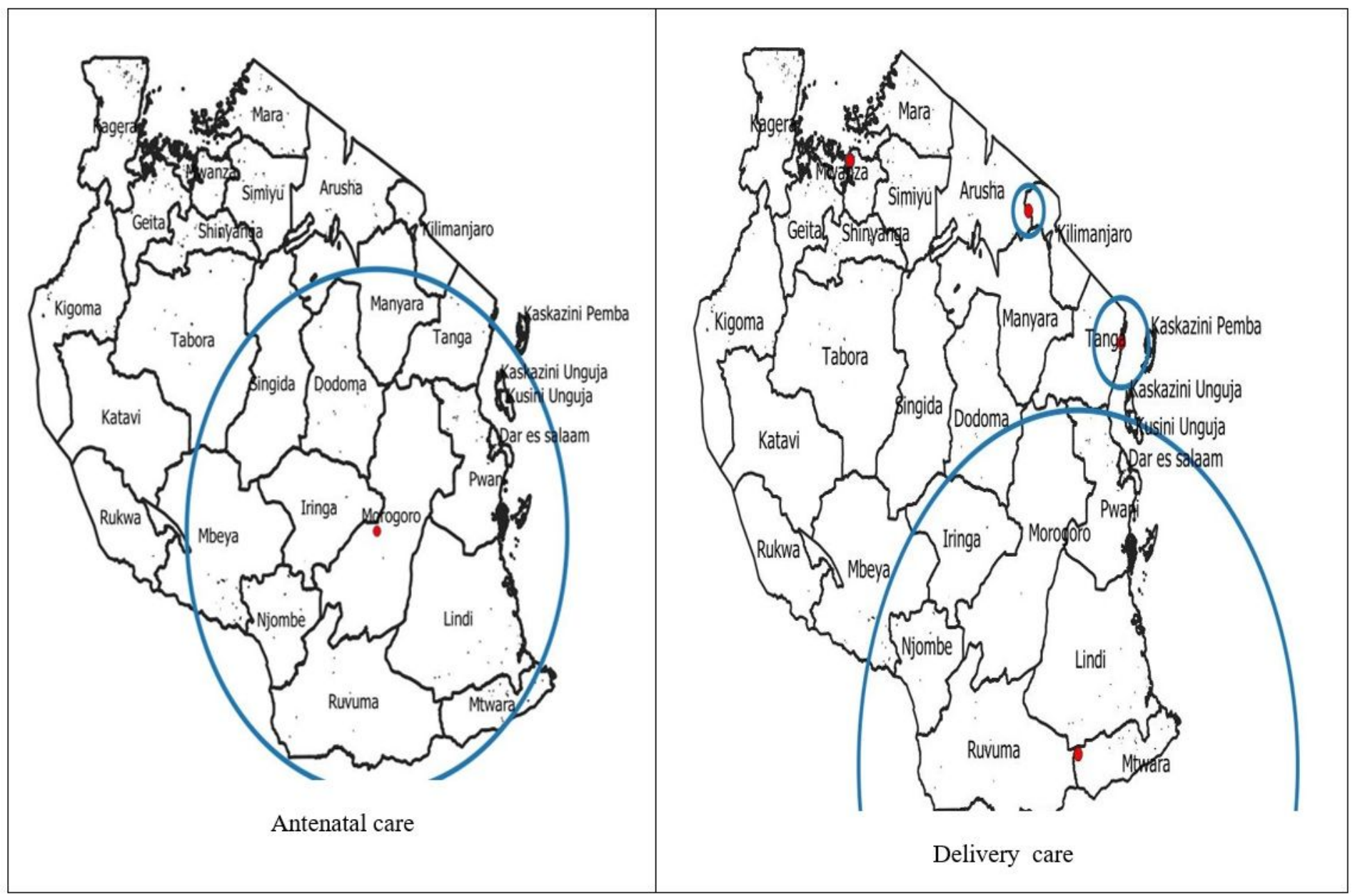

Figure 1

Clusters with the high utilization of antenatal care and delivery care from TDHS-MIS 2015-16 Note: The designations employed and the presentation of the material on this map do not imply the expression of any opinion whatsoever on the part of Research Square concerning the legal status of any country, territory, city or area or of its authorities, or concerning the delimitation of its frontiers or boundaries. This map has been provided by the authors. 


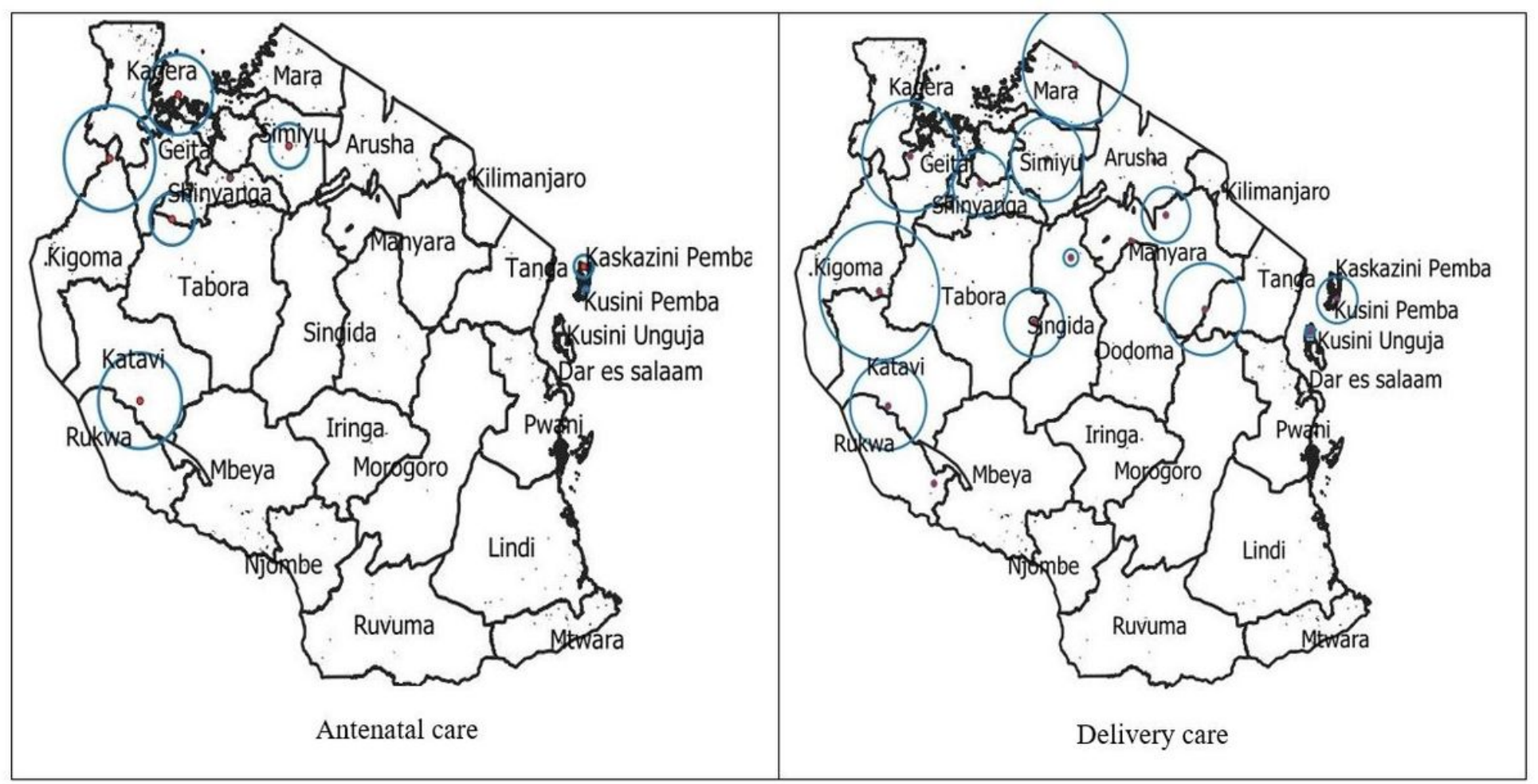

Figure 2

Clusters with the low utilization of antenatal care and delivery care from TDHS-MIS 2015-16 Note: The designations employed and the presentation of the material on this map do not imply the expression of any opinion whatsoever on the part of Research Square concerning the legal status of any country, territory, city or area or of its authorities, or concerning the delimitation of its frontiers or boundaries. This map has been provided by the authors.

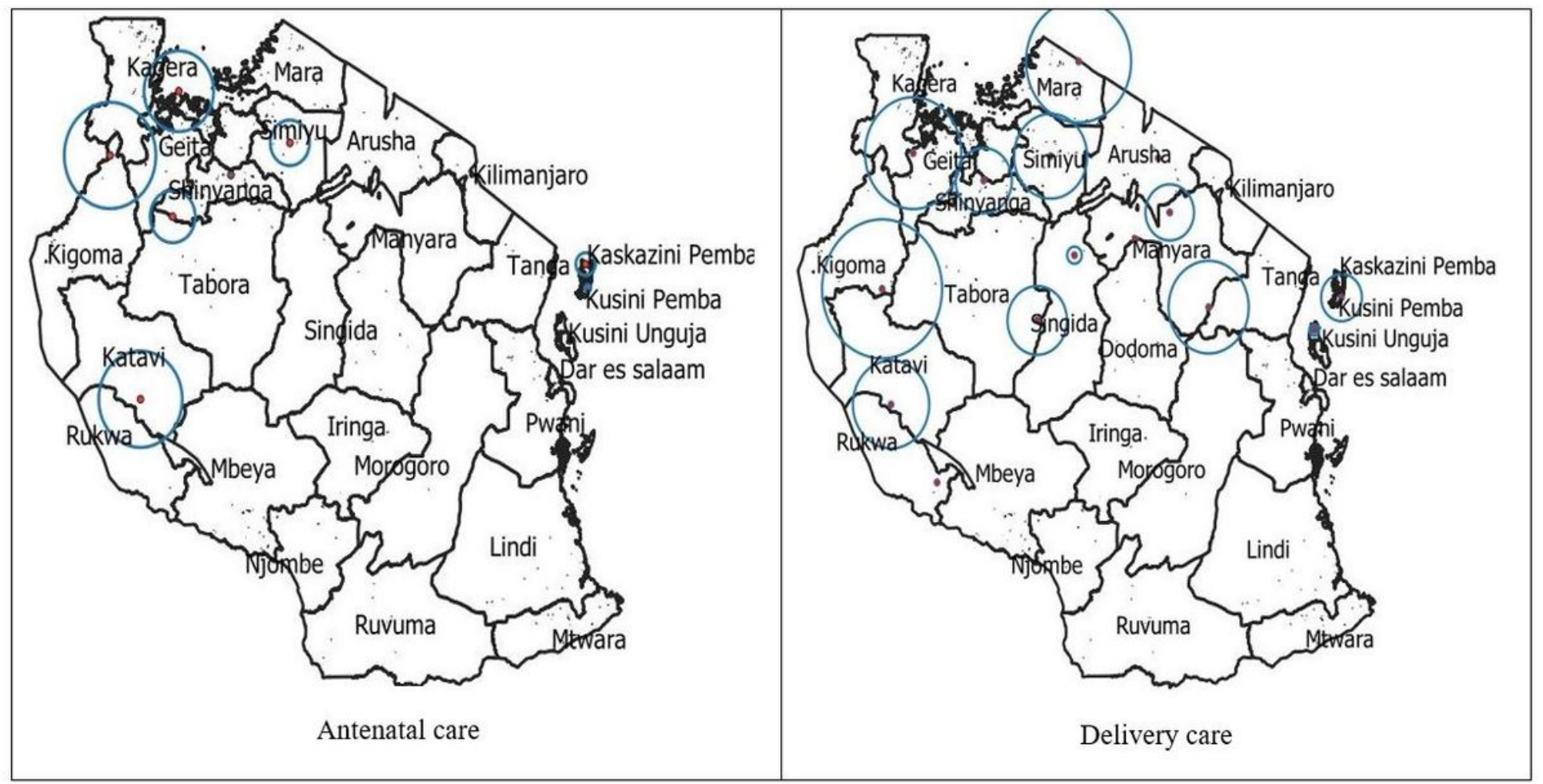




\section{Figure 2}

Clusters with the low utilization of antenatal care and delivery care from TDHS-MIS 2015-16 Note: The designations employed and the presentation of the material on this map do not imply the expression of any opinion whatsoever on the part of Research Square concerning the legal status of any country, territory, city or area or of its authorities, or concerning the delimitation of its frontiers or boundaries. This map has been provided by the authors. 